\title{
A TRANSITION FOR ALL
}

Equity and community engagement in the transition of water supply management to utilities in refugee settlements in Uganda

\section{JOHN ALLEN AND CAROLINE MUTURI}

This summary report was written to share research results, to contribute to public debate and to invite feedback on development and humanitarian policy and practice. It does not necessarily reflect the policy positions of the organizations jointly publishing it. The views expressed are those of the authors and not necessarily those of the individual organizations. A full version of this research report is available at the Oxfam WASH website: https://www.oxfamwash.org/ 


\section{CONTENTS}

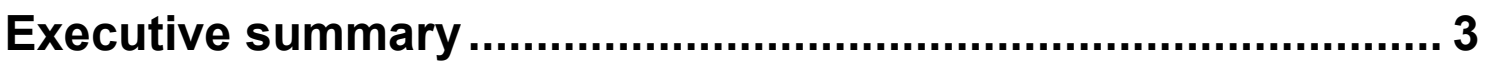

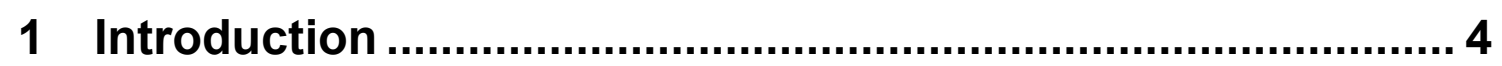

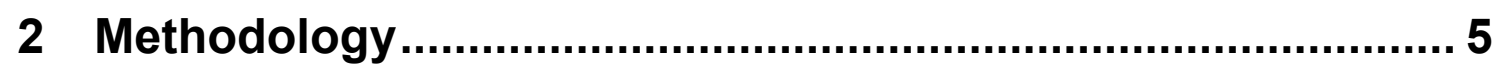

3 The current state of the transition ........................................ 6

4 Recommendations ............................................................ 15

5 Summary of Recommendations ........................................ 26

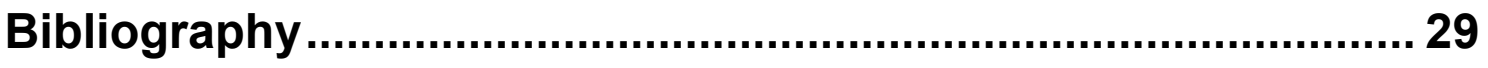

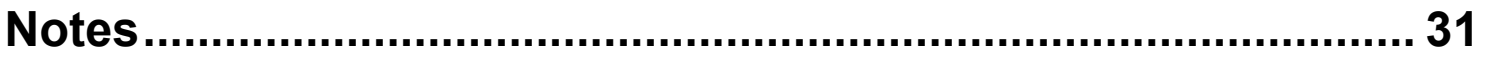




\section{EXECUTIVE SUMMARY}

Water supply schemes in refugee settlements in Uganda are being transitioned from management by humanitarian actors to management by national and regional utilities in an effort to improve their long-term sustainability.

A small number of water supply systems in the Midwestern and West Nile sub-regions of Uganda have recently come under the management of the National Water and Sewerage Corporation and the Umbrella Authorities. Efforts are underway between humanitarian and development partners to progress this further.

Research with refugee and host communities has demonstrated the need to strengthen the transition process. Current efforts by actors in the water, sanitation and health sector have focused on a range of aspects, including upgrading water supply systems in advance of their handover, identifying tariffs that refugee users can afford to pay, and building the capacity of the regional Umbrella Authorities. However, the transition in its current form could risk increasing inequality and pushing water services out of reach for an already vulnerable population.

Improving equity and inclusion goes beyond subsidized tariffs. In order to make the transition more equitable, participatory and effective, WASH agencies and stakeholders that are playing a supporting role in the utility transition should:

1. Enact equitable procedures on capital investment and tapstand operations. This includes making sure hardware subsidies do not favour the wealthy and that margins for public tapstands operators' income are fairly determined.

2. Develop sector-wide financial monitoring tools to track the key parameters of a successful transition, including the history of tariff payments, subsidies, operating costs and planned capital maintenance expenditures.

3. Carry out contextual understanding and risk analyses. These support tailoring utility transitions to local contexts and help lower the risks that come with beginning utility operations in a new area.

4. Engage communities and establish communications plans, community feedback mechanisms and opportunities for social accountability. Community engagement - including information sharing, consultation and involvement in decision-making - will allow end users to not only have a say in the services that affect them, but will contribute to more effective water supply management.

These recommendations do not encompass all areas needing to be addressed in the utility transition, but are focused on specific economic and community engagement aspects of the transition. Taken together, these steps can contribute to utility transitions that result in sustainable, equitable, inclusive and socially accountable water services. 


\section{INTRODUCTION}

Uganda hosts an estimated 1.4 million people originating mainly from South Sudan and Democratic Republic of Congo. ${ }^{1}$ To address the basic needs of this refugee population, NGOs have installed piped water supply systems that provide services to host communities.

Water service delivery in refugee settlements has mostly been provided by humanitarian agencies. To improve the sustainability of services, Uganda's Ministry of Water and Environment (MWE) and the UN High Commissioner for Refugees (UNHCR) have begun transitioning management to the country's existing utilities. They have agreed to begin charging water tariffs in refugee settlements as a part of this transition. These changes have been undertaken as part of Uganda's commitments linking humanitarian interventions with sustainable development and resilience for refugees under the Comprehensive Refugee Response Framework (CRRF) ${ }^{2}$ and the Refugee and Host Population Empowerment (ReHoPE) Strategic Framework. ${ }^{3}$ The National Water and Sewerage Corporation (NWSC) and regional Umbrella Authorities (UAs), the water utilities in Uganda, are now key actors in the delivery of water supply services in refugee settlements.

NWSC is a public utility company $100 \%$ owned by the Government of Uganda, established in 1972 to provide water and sewerage services across Uganda, focusing on urban areas. Under its mandate from MWE, it has expanded coverage, with a $300 \%$ increase in the number of people served between 2011 and 2019. ${ }^{4}$ NWSC has taken over operations of water supply in the Rwamwanja and Bweyale refugee settlements as part of an agreement with UNHCR.

The six UAs operate as companies limited by guarantee with a mandate to provide water and sanitation services in their respective regions: Southwestern, Karamoja, Midwestern, Central, North and East. Previously known as Umbrella Organisations, they provided technical support to local governments in the daily operation and management of water schemes. However, since restructuring in July 2018, they have been mandated by MWE to function as utilities involved in the day-to-day running of the schemes, including revenue collection. The Northern UA has assumed management responsibility for the Nyumanzi refugee settlement in Adjumani District. 


\section{METHODOLOGY}

This study seeks to generate insights on the transition to the management of water supply systems by utilities and develop recommendations to support the process. It combines literature review, key informant interviews and focus group discussions, held in Uganda in January and February 2020.

Four refugee settlements were selected for study: Rwamwanja and Kyaka II in Midwestern Uganda, and Rhino and Imvepi settlements in the West Nile sub-region. Water supply schemes were chosen in these settlements to capture a diversity of geography, locations where utility transition has begun and where it has not, different system sizes, areas with a history of tariff collection, and contexts in which the extent to which services are shared with host communities varies. In Rwamwanja, the transition to NWSC was taking place at the time of research. In Nyumanzi refugee settlement in Northern Uganda, the Northern UA had recently taken over management of water supply. Nyumanzi was not visited during the field research but was discussed in-depth with multiple stakeholders, including the manager of the Northern UA.

Discussions were held with groups of end users in Kyegegwa, Kyenjonjo and Kamwenge districts in the Midwestern sub-region, and in Arua and Yumbe districts in the West Nile. 16 focus group discussion were held with refugee and host community members, in separate groups of men, women and youth. They were held in the four refugee settlements.

Key informant interviews were held a wide range of water, sanitation and hygiene (WASH) sector stakeholders in Kampala and the two sub-regions. Government representatives from the MWE, the Office of the Prime Minister (OPM) and District Water Offices (DWO) were interviewed. Representatives of local management structures, both for water supply and overall administration, were also interviewed, including Water User Committees (WUCs), Water and Sanitation Boards (WSBs) and Refugee Welfare Councils (RWCs). Interviews were held with utilities, including UA national and regional staff and NWSC branch staff in Kamwenge and Arua. Humanitarian and development WASH actors, including donors, UN agencies and international NGOs (INGOs) were interviewed, including staff from GIZ, KfW, ECHO and UNHCR, IOM, Malteser International, Engineers Without Borders - USA (EWB), Water for People, and Oxfam. A complete list of agencies consulted is available in an annex to the full version of this report.

Interview questions focused on three main themes:

- Economic analysis to inform decisions on the transition;

- Community engagement on water-user tariffs; and

- Governance and accountability under a new utility management model.

A Transition for All: Supporting equity and community engagement in the transition of management of water supply systems to utilities in refugee settlements in Uganda 


\section{THE CURRENT STATE OF THE TRANSITION}

\subsection{CAPITAL EXPENDITURES (CAPEX) FOR OPTIMIZATION}

Upgrading existing piped water supply systems in advance of their handover to utilities is a major focus of WASH actors at this stage. This 'optimization' process includes:

- upgrading the water system to improve the efficiency of the system, build the production potential to supply more users, and boost revenue-generating potential;

- analysing water supply availability and demand against current infrastructure; and

- identifying cost-effective changes to most efficiently provide water to the target population.

Current capital expenditures (CapEx) include, among other improvements, the extension of private connections to households and businesses seeking their own tapstands. Users of private connections are not charged at the pro-poor tariff of public standposts, ${ }^{5}$ so contribute to the revenue-generating potential of the water supply system. However, due to a lack of prioritization for CapEx, private connections are being subsidized, even while other capital upgrade needs remain unmet. This raises the risk that the transition might benefit economically advantaged people and not the most vulnerable populations who still lack access to public connections.

The construction of communal prepaid water dispensers, also known as 'water ATMs', in refugee settlements is a nascent development in the sector. Some actors are promoting the allocation of CapEx budget toward prepaid dispenser installation in refugee settlements. Prepaid dispensers can contribute not only to revenue generation but can allow the introduction of tariffs for individual households, which are at first subsidized by service providers. The prepaid dispenser technology allows service providers to easily adjust tariff rates, and so subsidies can be gradually phased out and users may eventually be able to pay rates that are less subsidized over time. There is uncertainty over the willingness and ability of end users in different refugee settings in Uganda to pay for water. While studies have attempted to determine this, data from pilots is needed to more accurately capture willingness and ability to pay, including across different populations groups. Utilities and sector stakeholders recognize that tariffs need to be determined at rates that are able to generate sufficient revenue to meet operating costs and beyond, to contribute to the lifecycle costs of water service delivery. The data produced by newly installed prepaid dispensers offers an opportunity to determine evidence-based rates.

\subsection{COVERING OPERATIONAL EXPENDITURES (OPEX)}

Instituting user tariffs that generate revenue to pay for operational expenditures (OpEx) is the second major focus of WASH actors as part of the transition. OpEx costs include:

- energy;

- personnel;

- consumables, such as those for water treatment and cleaning materials; and 
- maintenance and repair of pumping systems, and transmission and distribution networks.

The present study and others ${ }^{6}$ have highlighted the lack of detailed OpEx data. Where information is available, it tends to be poorly or inconsistently documented, or based on estimates rather than historical expenditures.

According to information provided by the UAs, the refugee settlements require larger water supply systems - with more expensive and higher capacity pumping systems - than the others managed by the UAs. OpEx are similarly higher. On the other hand, NWSC considers the operational costs, such as in Rwamwanja, to be within the norm for systems that they operate. Analysis by the World Bank on six systems identified a very broad range of OpEx: UGX 279$17,390 / \mathrm{m}^{3}\left(\$ 0.07-4.57 / \mathrm{m}^{3}\right) .^{7}$

Water user tariffs (discussed in Section 3.4) are not being proposed as a source of revenue to cover additional costs, such as branch, regional or headquarters personnel. Given the affordability limitations for the vulnerable populations in refugee settlements, the challenge will be in instituting tariffs that cover basic operations and maintenance costs.

A major category of OpEx is paying the daily operators of public standposts (PSPs). These attendants are responsible for opening and closing tapstands, dispensing water and, in the absence of communal prepaid water dispensers, tariff collection. Despite their importance in the overall water service delivery model for refugees and host communities using public tapstands, little attention has been given to calculating expenses for running PSPs, nor determining how they will be financed. Tariffs have only been determined by utilities and sector stakeholders for the rate paid to the utility, and do not include the cost of PSP operators.

In the absence of enforcement, PSP operators in Uganda tend to act as middlemen who charge high margins, passing on high costs to users, often pricing them out of accessing safe water. ${ }^{8}$ Utilities, with their experience limited to typical water supply systems in Uganda, do not try to regulate or enforce the rates that PSP operators charge end users. Such micromanagement is neither practical nor relevant to their needs.

It is critical to set the income for PSP operators at a level that sufficiently incentivizes them to not abandon their duties for other opportunities, while bearing in mind that the additional cost will ultimately be borne by the end users. Analysis has not been conducted to derive appropriate margins for PSP operators. Given that PSP costs have the potential to double the amount that people must pay for water, according to utilities, these expenses must be calculated, managed and regulated. While this may not be possible in other settings in Uganda, it should be possible to do so in the context of refugee settlements given the presence of actors such as the Office of the Prime Minister, UNHCR, and NGO partners.

\subsection{CAPITAL MAINTENANCE EXPENDITURES (CAPMANEX)}

Capital maintenance expenditure (CapManEx) refers to the cost of replacing or carrying out major repairs on system assets. These replacement costs are different, and often more expensive, from the week-to-week, more predictable costs of basic operations and minor repairs that are included in OpEx. The ability to replace components when they reach the end of their lifespan, or in the event of a major breakdown, is a critical test of the financial management of water supply systems. However, achieving revenue levels that can even meet basic operating costs is a major challenge for this utility transition. Therefore, alternatives are needed for financing CapManEx.

In its present operations throughout Uganda, NWSC funds capital maintenance regularly, even for systems that are running at a loss. This is done by cross-subsidizing from more profitable

A Transition for All: Supporting equity and community engagement in the transition of management of water supply systems to utilities in refugee settlements in Uganda 
systems, such as those in cities. Any NWSC-managed system is eligible for this form of subsidy under its operating agreement. In order for this cross-subsidization to be possible, the water supply system must meet NWSC's criteria for technical requirements at the time that NWSC takes over management. For systems that have the potential to be transitioned to NWSC, making CapEx investments will contribute to their long-time financial sustainability, with future CapManEx financed through NWSC's nationwide operations.

The UAs have a mandate to focus on expanding service coverage, provide services to small towns and rural growth centres, and now to refugee settlements. Up until now, instead of crosssubsidization, UAs currently fund CapManEx through conditional grants from MWE, which are allocated to each UA as part of the annual budget cycle. However, UAs reported in interviews that this grant is typically used for smaller replacement and rehabilitation costs. When rehabilitation or replacement costs exceed conditional grants, they rely on ad hoc special requests to MWE.

However, the UAs mentioned in interviews that they now seek to cross-subsidize from within their regional operations. The cross-subsidizing approach is new to UAs, being introduced as a part of their transition to becoming utilities. According to the Midwestern UA, their tariff-setting calculation allows for income to exceed OpEx by approximately $10-20 \%$, which goes into a regional account to finance CapManEx. They intend to apply the same modality to water supply systems serving refugees as their entire portfolio of systems. The Northern Umbrella reports UGX $100 \mathrm{~m}$ monthly revenues against UGX $87-90 \mathrm{~m}$ in expenditures, noting with the $10-13 \mathrm{~m}$ balance to be applied for cross-subsidy, especially for water supply systems with high energy costs. However, they report that this tariff revenue is not sufficient for CapManEx, and that the other financing modalities from MWE are required.

The MWE uses the Utility Performance Management Information System (UPMIS) across water supply systems managed by the UAs. MWE intends to use UPMIS for asset management and investment planning. However, asset management has remained one of the biggest challenges in water supply management in refugee settlements, and the management, planning and budgeting of CapManEx needs support. Timeframes are needed for when system components, especially pumping systems, require major rehabilitation and replacement and for when budget will be allocated at the time that these expenditures occur. Water for People has been supporting the Midwestern UA develop this capacity through the CapManEx Costing tool, ${ }^{9}$ which provides year-by-year projections.

\subsection{WATER TARIFFS}

NWSC's tariffs are broken into categories (see Table 1), which are uniform across Uganda. They do not vary according to localized factors, such as cost to operate or population density.

Table 1: NWSC water tariffs (UGX), January 2020

\begin{tabular}{|l|l|l|}
\hline Customer category & $\begin{array}{l}\text { Tariff per cubic metre } \\
\text { (VAT included) FY } \\
\text { 2018/19 }\end{array}$ & $\begin{array}{l}\text { Price per jerrycan } \\
\text { (VAT included) FY } \\
\mathbf{2 0 1 8 / 1 9}\end{array}$ \\
\hline Public standpipe (PSP) & 1,060 & 25 \\
\hline Domestic & 3,516 & 83 \\
\hline Institution/Government & 3,558 & 84 \\
\hline Commercial $<1500 m^{3}$ per month & 4,220 & 99 \\
\hline Commercial > $1500 m^{3}$ per month & 3,373 & 79 \\
\hline Industrial <1000m per month $^{3}$ & 4,220 & 99 \\
\hline Industrial $>1000 m^{3}$ per month & 2,500 & 59 \\
\hline
\end{tabular}


The two tariffs that are being applied in refugee settlements are the PSP and domestic rates. Refugee and host community customers are charged at the same rates. NWSC branch managers interviewed for this study confirmed that their tariff structure does allow for crosssubsidization, and that refugee water users, particularly those accessing water from public tapstands, would be cross-subsidized in this way.

UAs' water tariffs are determined on a per-system basis, based on the cost of operation and maintenance. Tariffs are uniform within a single water supply system, i.e. there is no differentiation between user types, but vary between systems within regions. This is in line with the national tariff policy.$^{10}$ According to the Midwestern UA, tariffs range from UGX 1000$2500 / \mathrm{m}^{3}$ for gravity-flow schemes to UGX $3500-4000 / \mathrm{m}^{3}$ for pumping systems. Given the size of the water supply systems in refugee settlements, the Midwestern UA director estimated that these tariffs would fall on the upper end of this range; however, the tariffs needed to cover OpEx (and CapManEx) had not yet been calculated for these systems.

Tariff setting by UAs is a consultative process involving a range of stakeholders to check for affordability by intended end-users, approved by the MWE.

\section{Tariffs in refugee settlements}

For many years, refugees and host communities did not pay tariffs to access water, with operations being fully subsidized by operators, mostly INGOs. However, this has changed recently. WASH NGO implementers have been initiating monthly, informal water user fees in the range of UGX 500-2000 per household per month, with UGX 1000 being the most commonly charged user fee. These are not enough to cover monthly OpEx, a fact that is widely recognized by stakeholders, including refugee representatives on RWCs. The need to raise money has been included as part of the formation and training of WSBs in settlements by NGOs and UAs, and in the training given to WUCs, which are water user committees that have been created to manage tapstand operations. Nonetheless, the introduction of water user fees has helped to prepare communities for the transition. WASH actors have reported that they consider it a valuable transitional step that will make it easier to institute formal tariffs.

The tariff structure in Rwamwanja refugee settlement has been agreed between NWSC, which is currently managing the water supply system, and UNHCR in a Memorandum of Understanding (MoU). PSPs will provide water at the national pro-poor rate of UGX 25/jerrycan. Under the MoU, the first 20 litres (i.e. jerrycan) per person per day will be paid directly to NWSC by UNHCR. However, this means that - except for those regularly using more than 20 litres of water per day - this arrangement will not generate data on the willingness and ability of users to pay. As users begin to pay for water, data will be drawn from this experience. Early payment data is likely to much more indicative of willingness and ability to pay than projections derived from willingness-to-pay studies. Such information is greatly needed by the sector as the management of more water supply systems are transitioned to utilities.

In Nyumanzi refugee settlement, the Northern UA has assumed operational responsibilities and has instituted user tariffs of UGX $750 / \mathrm{m}^{3}$. This is the lowest rate in Uganda, at UGX $15 /$ jerrycan. The UA reports a $100 \%$ revenue collection efficiency in Nyumanzi for both private connections and PSPs so far.

However, there is a large gap between this rate and the UGX 25/jerrycan under the NWSC's pro-poor rate, before even accounting for PSP operator margins. There is even larger gap with the 3500-UGX $4000 / \mathrm{m}^{3}$ (UGX 70-80/jerrycan) typically required for UA-managed pumping systems to fully cover OpEx costs.

Willingness-to-pay studies have been carried out to assess the feasibility of instituting tariffs for refugees. ${ }^{11}$ Willingness-to-pay for water has found to be 500-1000 UGX/HH/mo. However, there is uncertainty on the extent to which willingness-to-pay survey data predicts actual

A Transition for All: Supporting equity and community engagement in the transition of management of water supply systems to utilities in refugee settlements in Uganda 
payment. Users may be willing to pay more, or ability-to-pay for some may be less. More complete information on willingness and ability to pay will come in the form of actual history of payment at the time that tariffs are introduced.

The WASH sector seeks to close the gap between the current user fee levels and the NWSC pro-poor rate, at a minimum, and preferably towards those charged for UA-managed pumped systems. Sector stakeholders, such as UNHCR, intend to identify initially suitable subsidized tariffs and gradually reduce the subsidies. However, assuming large subsidies are not feasible given the large number of refugees and the limited budget available in the sector, significant progress is needed on developing tariffs which refugees are able to pay to close the current gap. Developing tariff rates will be done through experience introducing and modifying these rates. This remains one of the main challenges facing the sector, with data needed from other systems transitioning in order to guide the process of reducing the subsidization of OpEx, with tariff revenues covering this in the long term.

\section{CUSTOMER RELATIONS}

NWSC's customer service charter ${ }^{12}$, established in 2016, details the standards of service delivery that customers should expect, and how they can seek improvements where NWSC fails to deliver.

The level of customer engagement varies between UAs. The MWE has a clients' charter ${ }^{13}$ (2018-21) that specifies the standards for delivery to which users have a right and sets out feedback and complaint-handling mechanisms. The UAs intend to provide readily accessible information on performance and usage statistics as part of their transition to fully fledged utilities. Currently, information on water system operations and finances is available online through UPMIS, which provides service information for individual water supply systems.

NWSC communicates to its customers regularly through various media outlets. The information shared includes procedures for getting connections, modes of payment, tariffs and the price of water provided by NWSC. The utility also conducts quarterly customer surveys and stakeholder workshops to assess customer needs. It receives and responds to all customer complaints through area offices' customer care desks during working hours, 24-hour toll-free telephone lines, and their website.

UAs communicate with customers through notices, brochures, media and ad-hoc communications by staff. SMS are used to send reminders for payment. UAs reported that communities in Uganda prefer face-to-face meetings to communicate with the UA. Based on their experience in Nyumanzi refugee settlement, the Northern UA recommend a minimum of four community meetings per month during the transition phase to ensure effective interactions.

The level of complaint management varies between UAs. Most complaints are received through walk-ins at UA offices or phone calls to the secretariat. The Midwestern UA relies on a customer complaint register run by their staff to check customer feedback. However, the complaints are not analysed, and there is no evidence that steps are taken to close complaints. The UAs reported that this will change when a web-based mechanism to collect and resolve customer complaints is introduced across the six UAs in 2020.

Across the country, both NWSC and the UAs offer automated billing. Bills can be paid through a range of mobile options. Customers are expected to pay for services within two weeks of receiving a bill. NWSC has a grace period of up to 30 days, after which a customer is considered a defaulter. UAs use dialogue whenever a customer delays to pay. If this fails, the service is stopped, and the UA may engage in legal proceedings as a final attempt to recover their payment. 


\section{COMMUNITY GOVERNANCE STRUCTURES}

Refugee welfare councils (RWCs) are political administrative structures within refugee settlements that mimic the local councils in Uganda's local government structure. Each RWC consists of 11 elective positions. The electoral process starts from the village level, with 11 members in the RWC1. Then at the zonal level, multiple villages elect members to the zone's RWC2. Finally, at the settlement level members from zones throughout the settlement elect members to the RWC3, which is the highest level of refugee representation in a settlement. The RWC3 represents the interests of refugees in the settlement, including on issues related to water supply, and reports to the Office of Prime Minister.

Water user committees (WUCs) represent end users and are responsible for the day-to-day running of a given water point. This study found WUCs were either elected by communities or selected by a WASH agency based on criteria such as proximity to the water point and knowledge on health matters. WUCs vary in size from two to seven, all working voluntarily. In most settlements, tapstands with several taps usually had a larger WUC with specified titles and roles for its members. The National Water Policy $(1999)^{14}$ provides for water source committees/WUCs or Water Boards/WSBs to collect funds for OpEx and CapManEx. In the absence of utilities, WUCs often perform this role as part of Community Based Management. ${ }^{15}$

Water and Sanitation Boards (WSBs) - which are being renamed Water and Sanitation Committees as part of the transition - are outlined in the National Water Policy. The MWE, through DWOs and UAs, relies on WSBs to support the management of piped water supply systems. Usually, the boards comprise of five to 11 members from local government and users, with at least $30 \%$ women representation.

The Midwestern UA supported the formation of a WSB in Kyaka II refugee settlement in December 2019, aimed at improving stakeholder involvement. If the proposed takeover by the UA is successful, the WSB will report directly to them on a daily basis, and help the UA to share relevant information with users, as well as advocate for users' water service delivery issues. The Kyaka II WSB includes members of refugee and host populations, as well as officials from local government, including the council clerk, LC3 (Local Council government) for host communities, and RWC3 for refugees). New WSBs were also recently setup in Rwamwanja and Imvepi settlements at the time of research in January - February 2020.

Figure 1: Relationship between structures in a water supply system managed by UA

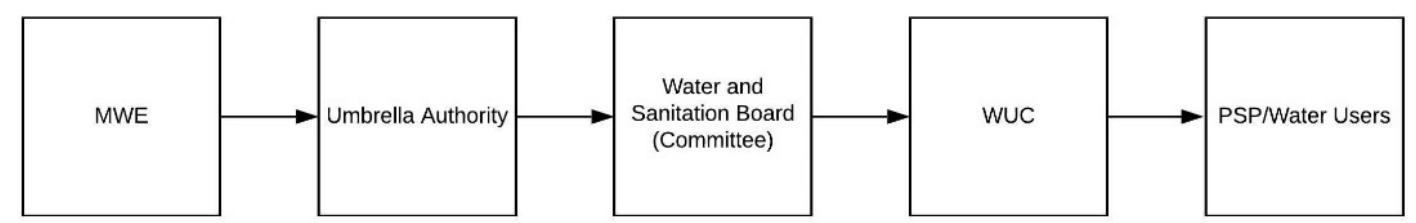

A Transition for All: Supporting equity and community engagement in the transition of management of water supply systems to utilities in refugee settlements in Uganda 
Figure 2: Current relationships between governance structures in refugee settlements

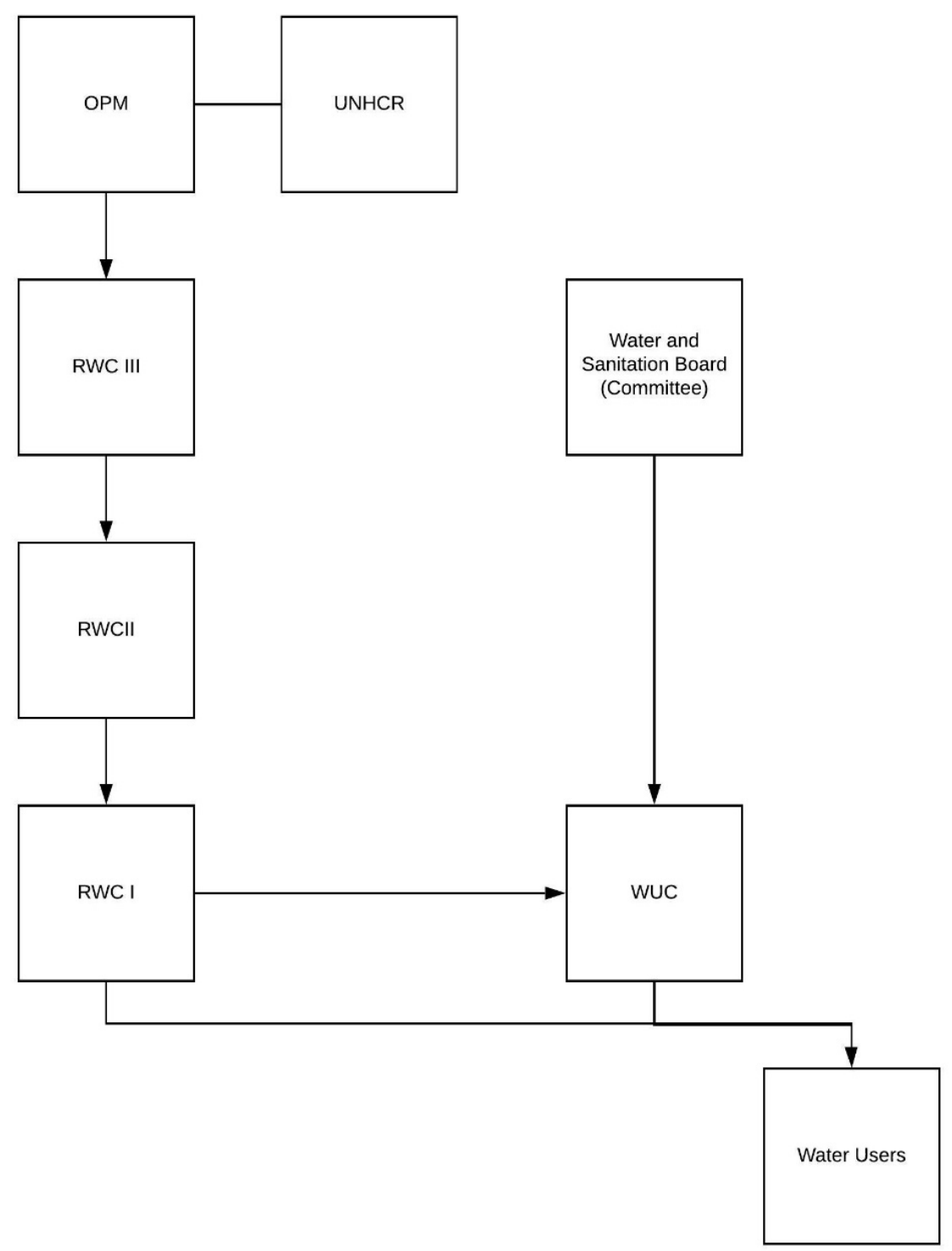

\section{COMMUNITY PERCEPTIONS}

Both refugees and host communities mentioned handpumps and tapstands as their main sources of water. Some of the issues reported by water users included:

- the unavailability of water due to rationing;

- broken tapstands and handpumps; and

- concerns about the management of the WUCs.

\section{Water user fees}

Generally, refugees in the Midwestern region were knowledgeable about water user fees; however, the concept appeared to be new in the West Nile region. In some areas, the WUCs enforced a 'no money, no water' policy at handpumps. At handpumps, point water sources that, unlike tapstands, are not connected to piped water distribution systems, water fees have been instituted by WUCs for local maintenance. Payment for water at handpumps has likely started earlier than payment at tapstands, as handpumps may have been handed over to WUCs, while 
implementing agencies have continued to operate and maintain piped schemes. This has forced users who could not afford user fees to walk long distances to fetch water from tapstands that did not enforce such a policy. In some cases, provisions are made for elderly and people with disabilities to collect water for free. Community members associated water user fees with the solving of basic water supply problems. The most common coping mechanism by communities in dealing with water shortages was collecting water from handpumps or fetching dirty water from swamps and seasonal streams. This is notable, as these are the sources of water that communities are likely to access if they are unwilling or unable to pay for water from piped water supply systems when tariffs are instituted.

Most refugees reported limited livelihood options in the face of various financial priorities such as food, clothes and healthcare. Refugees receive food rations or an equivalent of UGX 31,000 per head per month for food from the World Food Programme. In some settlements there were special programmes targeting the most vulnerable. Further, an allocation for water is made within the minimum expenditure basket agreed by the Cash Working Group - in other words, where refugees are supported with cash transfers, such as through ECHO-funded interventions, cash for water user fees has been included. However, these interventions target only a subset of the population in select locations and have not reached scale.

Host communities consulted in focus groups had mixed feedback on their ability and willingness to pay for water. A majority perceived themselves to be less vulnerable than refugees and were thus willing to pay slightly more than them. Water user fees collected were UGX 500-1000 per household per month, according to users, which was deemed affordable. In both refugee and host communities across the refugee settlements visited, the preference was for flat monthly water user fees no more than UGX 2000. Most refugees said they would be willing to pay for water if services were high quality - i.e. clear and safe water was available at all times at a nearby tapstand, with limited queueing time - and they had livelihoods opportunities to increase their income.

The discussion on communities' preferences regarding receiving cash or vouchers for water (assuming funds were available for either) split along age, gender and geographical lines. A key trend that emerged was a slight majority of men preferred cash, which they argued was better because of its multiple uses, while women largely preferred vouchers because of their negative experiences with cash given for food.

There were two distinct motivators among refugees and host communities for compliance in the payment of water user fees: fear of being denied water or paying hefty fines, and knowing that the cash collected improved the management of water points. Refugees and host community members recommended two options for dealing with non-compliance: make water free to everyone, and thus avoid issues of non-compliance all together, or enforce a 'no cash, no water' policy, by which operators issue receipts for cash paid by users.

\section{Communication}

The refugee community recommended different communication channels for dealing with water supply issues, including discussions with RWCs first, then with block leaders, and finally using hygiene promoters, who are community members appointed by NGOs for engagement related to water, sanitation and hygiene. Host communities mentioned community meetings of groups of households using a given tapstand as their preferred means of engagement with water utilities or relevant agencies. NGOs were the most trusted sources of information by refugees. Therefore, refugees suggested joint meetings be held by the utilities and the NGOs currently involved in water supply, in the presence of their RWCs. The RWCs preferred to be engaged first on the proposed transition, including understanding the policies and processes followed by the utility.

A Transition for All: Supporting equity and community engagement in the transition of management of water supply systems to utilities in refugee settlements in Uganda 


\section{Administration and management}

There were higher levels of satisfaction among refugee communities with RWC1s than WUCs, because all refugees participated in the election of RWCs, whereas WUC members were sometimes selected by NGOs based on their proximity to water points. The main concern among users was a lack of proper record-keeping by WUCs after user fees had been paid, with a majority recommending the issuing of receipts by the WUC treasurer. Communities had no objections to WUCs collecting water user fees if those WUCs had been elected in a transparent manner involving the RWCs and NGOs.

The WSBs in Kyaka II, Rwamwania and Imvepi settlements were new, so host and refugee communities were not aware of them and could not assess their performance. In some locations, there was evidence of collaboration between the WSB and WUCs, and a clear expenditure plan for the water user fees collected, although it was unclear whether this had been communicated to the users.

None of the communities consulted were aware of the utilities and the current or future role of the UAs or NWSC in managing water supply - even the host communities. WSBs were aware of the utilities that participated in their formation and training. Communities expressed an obligation to accept the transition to water supply management by utilities if doing so was UNHCR's policy. 


\section{RECOMMENDATIONS}

The transition is ongoing, with lessons being learned as the process continues. Several areas for improvement have emerged, which could lead to a more equitable, participatory and ultimately effective transition. The four key actions are:

1. Supporting a more equitable utility transition through procedures on CapEx and tapstand operations.

2. Developing sector-wide financial monitoring tools for measuring the key parameters of a successful transition.

3. Carrying out contextual understanding and risk analyses.

4. Supporting a more inclusive transition by engaging communities and establishing communications plans, community feedback mechanisms and opportunities for social accountability.

The recommendations listed here do not include every action that must be done as part of the utility transition. They are meant to contribute to the range of sector initiatives that are being undertaken to support an effective transition.

\subsection{EQUITY}

Two steps are required in order to support a more equitable transition:

- Establish tools for prioritizing capital investment to ensure an equitable transition.

- Develop a process for determining and harmonizing tapstand operator margins.

\section{Tools for prioritizing capital investment}

The allocation of public resources for water supply system CapEx contributes to both the sustainability of systems under their future management, and to improved equity in access to safe water. Capital investments that impact all water users should be prioritized, especially where service levels remain low.

At present, there is a risk that capital investments in some of the water supply systems being transitioned will only benefit the economically advantaged. This is the case where CapEx is being focused on infrastructure for individual private connections, even while many others do not have access to piped water at all. This risk exacerbating inequality. In a global review of subsidies for water and sanitation services, the World Bank identified that 'subsidies designed to ensure a minimum level of water consumption among poor households rarely achieve this goal, but instead tend to disproportionately benefit the wealthy'. ${ }^{16}$ Providing subsidized private connections in refugee settlements in Uganda is likely to benefit the most wealthy and not people living in poverty, who are unlikely to be able to afford either the subsidized connection fee or the domestic tariffs under the NWSC and the UAs.

Recommendations have been made elsewhere that utilities in Uganda should either offer users the opportunity to pay for private connections,,$^{17}$ or that these upgrades and connection fees should be subsidized..$^{18}$ On the other hand, for reasons of equity described above, we recommend that these costs should not be subsidized, unless targeted to the vulnerable, such as people with disabilities. However, offering people the opportunity to pay their own connection fees may be an equitable strategy, as long as complementary investments are made to ensure water supply access for all at public tapstands.

A Transition for All: Supporting equity and community engagement in the transition of management of water supply systems to utilities in refugee settlements in Uganda 
In order to have a more equitable transition, a WASH infrastructure and economics specialist from an agency supporting the transition should develop tools to guide the prioritization of CapEx. A tool such as a decision tree, with a number of parameters based on the context, can guide decisions on upgrading and optimizing water supply systems. Fully costed case studies can also be used as examples for system upgrades. Together, these can guide decision makers away from regressive subsidies that help only the wealthiest members of the community.

A system upgrade decision tool should be tied in with current efforts by UAs, GIZ, and EWB to establish system audits and performance improvement plans and should draw on the capital investment needs data generated through those exercises. Examples from the system audits can demonstrate the range of different upgrade types, the cost for each upgrade, and the cost per beneficiary. Fully costed examples will demonstrate the missed opportunities if informed decision making on CapEx is not followed and show when it is appropriate to offer private connections.

\section{Process for determining and harmonizing tapstand operator margins}

Little progress has been made on determining what income PSP operators should generate from their duties, and how these costs should be passed on to the consumer. The exception to this is the 1:3 (PSP : utility) income-sharing rate implemented by the Northern UA. A more systematic approach is required, especially for settlements where supplies are transitioning to management by NWSC. A current risk is that PSP margins will be high, and that these costs will be passed on to end users, pricing them out of water access. This is based on experience from informal settlements in Kampala, where this happened under NWSC systems, before prepaid meters were introduced. ${ }^{19}$

Effort is needed to equitably determine PSP operator rates, in the same way that efforts have been undertaken to determine tariffs. Refugee settlements offer the type of environment in which the regulation of set rates - and dissemination of this information - is possible. It should be feasible to establish settlement-wide PSP margins and end-user tariffs, and to communicate these widely. This will avoid risks of PSP operators driving up the price of water due to their position of control and limiting access for the most vulnerable.

The rates should be determined in a process involving all the relevant stakeholders, including utilities, PSP operators, WUCs, WSBs, RWCs, OPM, WASH actors and end users. Likely this could be done alongside the multi-step tariff consultation process that is already being followed in areas in which the UA is assuming management. Rates should be established that will provide enough financial incentive for PSP operators to take on responsibilities, but that do not price out end users.

The approach to setting these rates must accommodate the fact that tapstands provide water services to a range of different population sizes - and therefore can vary in their incomegenerating potential. It is recommended to use data on the current populations served by tapstands to arrive at acceptable margins. A distribution graph of the volume of water dispensed per tapstand (or households/population per tapstand as a proxy) can be plotted, in order to identify suitable cut-off figures, less than which will require specific consideration for costsharing/subsidization. 


\subsection{FINANCIAL MONITORING}

Five steps are required to effectively measure the key parameters of a successful utility transition:

- Establish a monitoring and learning tool for assessing the transition of prepaid communal dispenser tariff payments.

- Establish a sector-wide approach to testing and introducing tariffs and subsidies in systems without prepaid dispensers.

- Develop a common template and system for tracking OpEx, and share these widely with sector stakeholders.

- Adopt a sector-wide asset management system for planning capital replacement schedules and budgets.

- Reach consensus across the sector on the intermediate introduction of informal water user tariffs in locations where utility transition has not yet begun.

\section{Monitoring and learning tool for assessing the prepaid communal dispenser payment transition}

Prepaid communal water dispensers allow water user tariffs to be introduced and subsidies to be gradually removed, due to the ease with which service providers may adjust tariffs through the communal dispenser operator platform. While the level of tariffs that refugees in Uganda can pay has been measured through willingness- and ability-to-pay studies, ${ }^{20}$ the right level of user fees will only be determined through the actual experience of instituting tariffs, which is likely to provide a much more reliable source of data than surveys. Ultimately, the long-term sustainability of the water supply schemes will be strengthened when all water users are paying tariffs that generate sufficient revenues to cover all OpEx, and even contribute towards CapManEx. The tariffs being introduced at this point are subsidized. Sector actors hope to gradually reduce those subsidies without negative impacts on household water use.

Prepaid dispensers provide benefits in terms of the effective collection of tariffs, transparency and generating detailed performance data. Pilot prepaid dispenser interventions are beginning in Rwamwanja and Kyaka II and provide an excellent opportunity for learning and documenting key parameters for financial performance and other technical parameters, such as non-revenue water (or, water that has not been accounted for). Prepaid dispensers will generate not only financial data but also data on water usage, or at least collection, by end users. An important discovery will be at what tariff do households, especially those living in poverty, reduce their water consumption below levels required to meet their basic needs. It is recommended that a tool be developed which may document whether prepaid dispensers are contributing towards an effective process of introducing tariffs, by measuring the extent to which refugees and host communities are paying water user fees and collecting water to meet basic needs.

Establishing these variables should take a sector-wide approach, with multiple stakeholders providing input and agreeing on the monitoring variables and metrics of success. This will contribute to the process of gradually reducing subsidies and inform which tariff increases (or subsidy reductions) can be made, and what additional subsidies can be targeted at the poorest and most vulnerable people. A strong evidence basis will be needed for such decisions. The pilot interventions should seek to answer whether prepaid dispensers can contribute towards an effective transition.

A Transition for All: Supporting equity and community engagement in the transition of management of water supply systems to utilities in refugee settlements in Uganda 


\section{Sector-wide approach to testing and introducing tariffs and subsidies in systems without prepaid dispensers}

While prepaid dispensers present technology options through which the tariff and subsidy process can be refined, they are not the only way. There are capital cost barriers to implementing prepaid dispensers at scale throughout the refugee settlements in Uganda within a short-time frame. The formal introduction of tariffs based on metered volume collection are already taking place in their absence. Critically, data is now being generated from these early transitioning systems.

For example, as mentioned in Section 3.4, the Northern UA is charging a rate of UGX $750 / \mathrm{m}^{3}$ in Nyumanzi - as of February 2020 a $0 \%$ default rate has been reported by the utility. In Rwamwania, since February 2020, NWSC has agreed to provide water to refugees at the national pro-poor rate of UGX 25/jerrycan, with the cost of the first 20 litres per person per day covered by UNHCR. Establishing a system to measure performance is now needed to inform future transitions and determine appropriate tariffs and plans for subsidization.

It is recommended that nationwide data monitoring tools are established by utilities and WASH actors supporting them to fully capture the experience and payment history where tariffs are introduced in refugee settlements. This should include data such as tariffs charged by the utility, any additional margin charged by PSP operators, and the rate of default for water users. Similar to the data collected from prepaid dispenser pilots, this should be supported by additional technical data on water consumption, to measure whether tariff introductions are reducing water consumption below basic levels. The data from all refugee settlements in Uganda should be the basis for determining the timing and scale of subsidies, eventually leading to final nonsubsidized tariffs set on the basis of actual operation and management costs.

Specific subsidies are recommended for people on the basis of vulnerability profiling. The criteria for qualification and percentage of the population receiving such subsidies should be similarly documented, to further inform specific subsidy regimens targeted at vulnerable individuals. Where multipurpose cash is provided, and provision is made for water in the minimum expenditure basket, its effectiveness should be measured, especially for the poorest and most vulnerable, to inform further expansion of these interventions to support the gradual phasing in of tariffs.

\section{Common system for tracking operating costs}

With much of the emphasis of OpEx on cost recovery through tariffs in the transition process, this key metric should be measured and shared widely with utilities, humanitarian agencies currently managing water supply systems, and other WASH sector stakeholders supporting the utility transition. Tracking actual expenditure over time while systems are under utility management will be useful for several reasons. First, it will be possible to compare OpEx for individual systems while they have been managed by NGO operators versus utilities. This can provide quantitative evidence to justify whether utility operations reduce running costs.

Second, a key measure of financial sustainability of the utility transition will be whether tariff revenues meet or exceed OpEx costs as subsidies are reduced. OpEx data should be documented alongside measurements of tariff revenue and PSP margins as suggested above.

It should not be challenging to agree on a sector-wide template to use for documenting OpEx alongside water production, with categories including:

- energy costs;

- personnel costs;

- consumables; 
- transportation; and

- preventative and curative maintenance. In addition, CapManEx should also be tracked, as a part of asset management, and this is discussed in the subsequent section.

At the time of this study, a template had been made as part of the World Bank and UNHCR's work on transfer of services to authorities. ${ }^{21}$ This template could be the one that is standardized. Agreeing on a template for the whole sector could make it easier to include in contract agreements with utilities as part of transitions. They can state what costs will be shared by utilities with UNHCR, or another authority that may contract them, on a monthly basis, and then be disseminated across the sector. This will help WASH actors assess the financial performance of the transitioned water supply systems. Having this data available on a monthly basis could also improve transparency for end users and their representatives, especially the settlement-level WSBs. This could contribute to greater understanding among end users of the costs of the service that they are using, and thereby ease in the transition to tariffs and then to tariffs in which OpEx costs are not subsidized. Nationwide data will contribute to the evidence basis of the financial sustainability of utility-managed water supply systems in refugee settings.

\section{Sector-wide asset management system for planning capital replacement schedules and budgets}

The ability to plan for future large-scale capital replacement is a major factor in the long-term sustainability of water supply systems. Allocating resources for upgrading system components in advance of handing over operation to utilities is a major focus of the sector in the current phase of the transition. In the absence of an asset management system in which capital maintenance expenditures are scheduled, there are risks that services will be disrupted in the event of a sudden breakdown, possibly with long lead times before system components can be replaced.

NGOs, such as Water for People and Engineers Without Borders - USA, have been supporting the Midwestern UA in developing such tools for planning capital maintenance. The Northern UA has been supported in this by GIZ. This will be of particular benefit to the UAs, not only in their overall development as service providers across Uganda, but in their ability to manage the large capacity water supply systems with more expensive components that are in place in refugee settlements.

Whether financed from MWE's budget, as it is now, or from other sources such as tariff revenue and/or cross-subsidization, the scheduling of capital maintenance is necessary. It should be part of a standardized asset management system. The CapManEx costing tool developed by Water for People and Agua Consult for the Midwestern UA can be used to support MWE to include planned capital replacements in annual budgets. The UPMIS can be used together with the CapManEx costing tool, with inputs from the sector stakeholders involved in utility capacity building on asset management.

A single tool should be adopted across the sector. This will help MWE to plan budgets for replacement of assets according to the CapManEx schedule. Agencies and donors involved in the transition of specific water supply systems should ensure that:

- such a tool is operationalized;

- utilities are trained in its use at the time of handover; and

- there are provisions for the long-term financing of CapManEx in UA-managed systems.

A Transition for All: Supporting equity and community engagement in the transition of management of water supply systems to utilities in refugee settlements in Uganda 


\section{Reach consensus on the introduction of informal tariffs in locations where the transition has not begun}

Given the shortcomings of community-based management in large-scale refugee contexts, ${ }^{22}$ especially with problems in the lack of competent and transparent management of finances by voluntary committees, the practice of implementing informal tariffs in refugee settlements presents risks. Perhaps most significantly, refugees paying for services requires trust: if users pay for a service, they must get something in return. There should be a high quality of service provision without significant disruptions. If tariff collection begins in a haphazard way, without a corresponding improvement to service provision and reduction in downtimes, community trust can be eroded, which may lead to fewer users paying for water.

Despite such risks, stakeholders have gone ahead with this ad hoc approach. For the utility, it offers advantages of easing their process of charging tariffs: if users are already used to paying for water, they will be less resistant when the utility begins billing them. NGO stakeholders also see advantages to gradually easing in tariffs. Doing so will acclimate users to paying for water, starting with the low rates that households are paying now, and in most cases without any consequences in the absence of payment.

These risks and opportunities need to be weighed and a decision made on how water user fees should be introduced in the short term. If water user fees are to be introduced as part of a temporary community-based management structure, then this needs to be agreed upon by WASH sector leaders involved in the transition, including the rates that are charged, where rates are introduced at what times, and who the appropriate bodies are for managing the finances in the short term. This would need to be communicated widely to all stakeholders. To prevent some of the potential negative effects, intermediate systems for transparency should also be put in place, with regular figures on amounts collected, spent and saved made available to a full range of actors, including end users.

\subsection{CONTEXTUAL ANALYSIS AND RISK ANALYSIS}

Two steps are required to tailor utility transitions to local contexts and lower risks associated with new utility operations in an area:

- Engage with social scientists at early stages of the transition process to conduct in-depth community profiling.

- Develop a risk management plan, based on the probability and impact of the risks analysed, and review it periodically throughout the transition process.

\section{Engage with social scientists at early stages of the transition process to conduct community profiling}

Stakeholders should continuously seek better contextual understanding, using primarily qualitative approaches to identify formal and informal stakeholders, trusted information sources and providers at community level.

The two regions studied, Midwestern Uganda and West Nile, differ socioeconomically. Stakeholders should not assume one model for transitioning the water provision services will fit all. Instead, approaches should be informed by in-depth contextual analyses. A pivotal aspect in this case is understanding the motivators and barriers for payment of water rates in a given community. Efforts should build on steps that the community is already taking, as this encourages sustainable behaviour change, makes communities feel valued and involved, and makes them more likely to take up new suggestions. 
After identifying the motivators and barriers, the next step is to identify trusted information sources at the community level who can easily and quickly influence others. These individuals may differ between population groups. This study identified RWCs as being trusted by communities, but this should be evaluated at each settlement. Experts with backgrounds in social science, formative research and qualitative data collection and analysis are best suited to conduct the contextual analysis needed. Utility staff may require training to be able to carry out this analysis as new water supply systems come under their management. Inputs on the community profiling should be tailored to specific context needs. This process should complement population profiling, whereby tools are deployed for measuring the vulnerability of individual households.

\section{Develop risk management plans}

It is recommended that the implementing WASH actor alongside other relevant stakeholders analyse all the possible risks of the proposed transition. Stakeholders should rely more on qualitative data, and ensure there is an interactive risk analysis building on information as it is gathered, as opposed to a one-off event, for example at the start of the transition process.

The risk analysis process should be replicated at every settlement before a utility transition takes place. We recommend a one- or two-day workshop involving key WASH actors and others with knowledge of the community context(s) to develop this risk analysis and mitigation strategy. The risk management plan should be reviewed and updated periodically, approximately every three to four months.

\subsection{INCLUSION}

Five steps are needed to enable inclusion, participation, and accountability:

- Create and implement a communications strategy targeted to the specific needs and languages of the population.

- Develop and deploy a tool for measuring community participation.

- Support social accountability by creating lists of key information that end users have a right to know.

- Develop detailed referral pathways according to an agreed governance structure.

- Empower existing community structures to advocate for meeting their water needs.

\section{Create a communications strategy targeted to the specific needs and language of the population}

Stakeholders should create space for two-way communication with communities, allowing for the sharing of relevant information and listening to feedback. Before the transition, existing WASH actors in a given settlement (such as UNHCR and its implementing partner) should develop a communication plan jointly with the utility.

There are three basic steps in developing a communication plan: planning, implementation and monitoring.

During the planning phase, five questions should be answered:

- What information needs to be shared? (Message)

- Why is it necessary? (Objective/purpose)

- With whom are you communicating? (Target audience)

A Transition for All: Supporting equity and community engagement in the transition of management of water supply systems to utilities in refugee settlements in Uganda 
- When will you communicate? (Timeline frequency)

- Which channels will you use? (Media)

The planning should factor in the scope, schedule, budget and expected deliverables of the transition process. It is advisable to include an array of communication channels in line with the preferences, trust levels, literacy rates and access of different community groups, including the most vulnerable people. This ensures that messages can reach many people in refugee settlements, for example through local radio, social media, information/picture boards, etc. People need to relate the information to their real lives through discussion and questioning, so opportunities for face-to-face dialogue are vital. Consultations with communities during this study identified face-to-face meetings as their most preferred channel of communication, and RWCs and NGOs being the most trusted bodies. However, this should be evaluated at each settlement where a utility transition is taking place. Ideally, the answers to the five questions above should be based on a risk analysis and contextual understanding.

As soon as the WASH sector agrees on guidelines for a transition, we recommend developing written communication for wider circulation, covering such aspects as water tariffs and customer support. The next step of the communications strategy will focus on the creation of content and development of information, education and communication materials (IECs), starting with the collection and analysis of existing contextual data, as described in the section above. The content creation process should draw from existing materials, such as the WASH IECs used by WASH agencies in the refugee settlements and the utility in the host community. The design and distribution of messages should be influenced by communities' literacy levels, language and cultural preferences. It is recommended to test any new IEC developed within a small group of the targeted audience before mass production for wider circulation. Messages shared with the community should be reviewed and updated on a regular basis, to ensure relevance and accuracy as the context changes.

\section{Develop a tool for measuring community participation}

The participation of end users can support the behaviour change needed to create a culture of paying for water. Therefore, stakeholders should invest in the measurement of community participation in each transition. Inclusive community participation that involves women in decision making processes on changes that affect them is a necessary condition for social accountability. WASH actors must remain accountable to communities, by addressing complaints and closing the feedback loop.

WASH actors, including water utilities, should create opportunities for meaningful and measurable participation at all stages. Participation should be measured in:

- the setting of water user fees in areas where the transition is yet to start;

- the tariff-setting process in areas where transition is confirmed; and

- the site selection for new PSPs where water supply systems are being expanded

WASH leaders should develop and test a community participation measurement tool in the water supply systems that have already transitioned as part of a monitoring plan. Indicators for measuring community engagement must include participation and user satisfaction with projects' intended outcomes. Using common community engagement indicators adapted for the context will enable the WASH actors to gather evidence of effectiveness, which can provide information on the costs and benefits of effective community engagement interventions during the transition. The data obtained should be used to influence other stakeholders, such as donors, and lobby for resources to deliver community-centred activities at scale in transitions in other settlements. WASH leaders should take responsibility for ensuring participation is measured in a monitoring and learning plan, ensuring that the lessons learned are widely shared among relevant stakeholders and applied in future transitions. 


\section{Support social accountability by creating lists of key information for end users}

Improving accountability in water service provision requires social, political, administrative and financial efforts. Social accountability specifically refers to actions taken to hold key decision makers to account. Social accountability mechanisms provide extra checks and balances on an issue in the public interest. Table 2 provides examples of the kinds of information that should be provided to end users to support social accountability.

Table 2: Examples of information to be provided to end users

\begin{tabular}{|l|l|}
\hline For what? & Do refugees and host populations know what they have a right to (with \\
& regards to water service provision)? \\
& Can refugee and host populations access the information they need \\
from UNHCR and OPM? & Do vulnerable groups have access to and use information from the \\
utility and WASH NGOs through their offices or broadcast media? & Are application forms for access to a subsidy, water connection or other \\
& service provided in languages understandable to those entitled to it? \\
\hline Is evidence (data) collected about policy outcomes made publicly \\
available, in a user-friendly format, and using means of communication \\
that are easily accessible by people living in poverty, women and other \\
vulnerable groups (e.g. through community meetings or radio)?
\end{tabular}

Transparency and meaningful participation contribute to improved accountability. Increased access to information enables communities to scrutinize the work of utilities, and put pressure on the latter to be accountable, perform better and shun corruption. The community needs transparency on water quality, pricing and tariff structures; the availability of subsidies for marginalized groups and individuals; systems for paying bills; and the contents of communication plans.

\section{Develop detailed referral pathways}

It is important that water users are able to give feedback and raise concern through clear referral pathways, determined according to a clear governance structure.

The two water utilities in this study have well-defined governance structures. The NWSC prefers to deal directly with PSP operators, while the UAs use WSBs as a framework for community

A Transition for All: Supporting equity and community engagement in the transition of management of water supply systems to utilities in refugee settlements in Uganda 
representation, in addition to their direct interaction with customers. During consultations, the community's preference was to have a say through RWCs, their most trusted structure. Thus, it is recommended to have a clear link between the utilities and communities through the existing RWC structure for refugee community representation. An illustration of the proposed governance structure based on stakeholders' feedback is shown in Figure 3.

\section{Figure 3: Proposed governance structure among actors in utility transition}

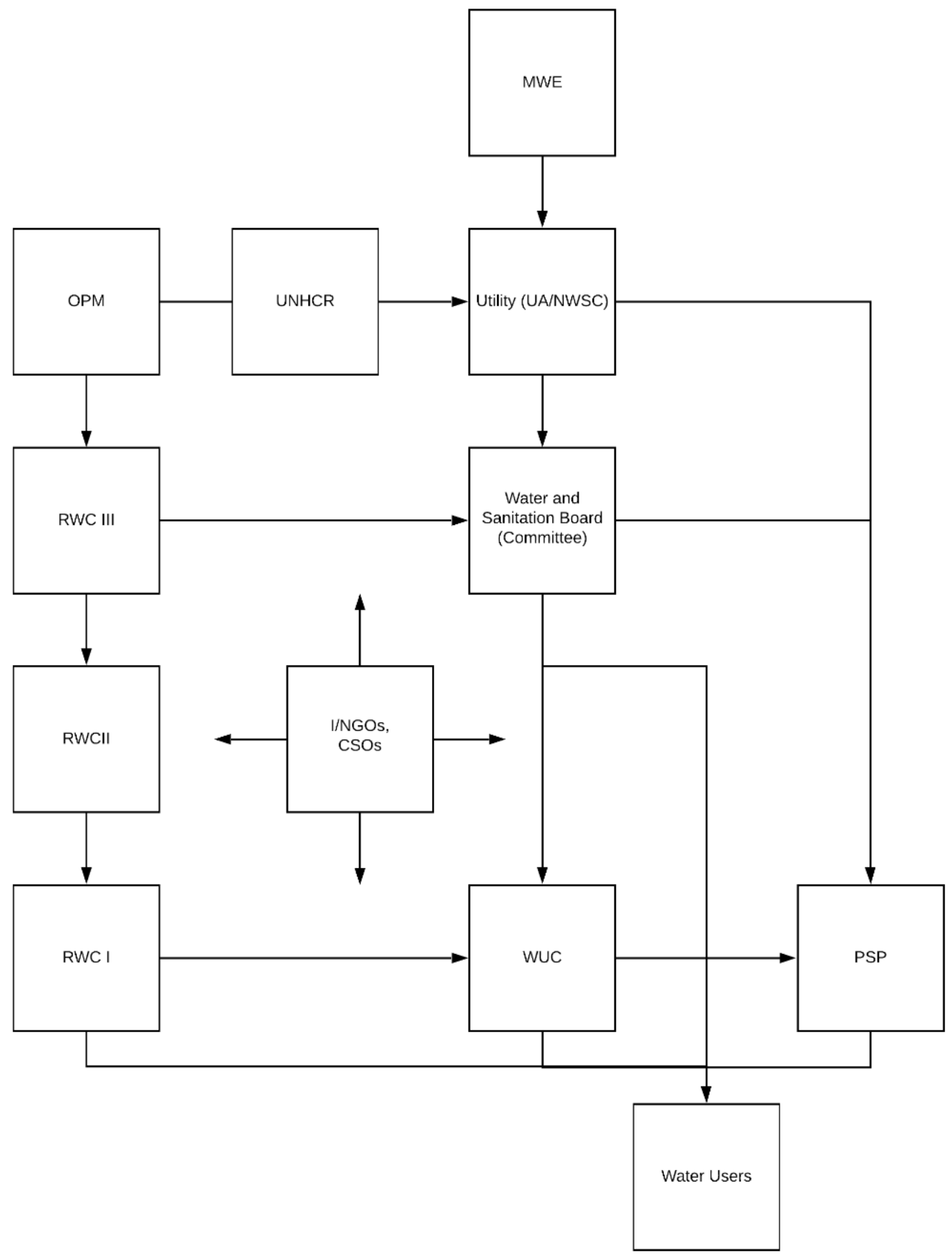

It is recommended that the WASH agencies playing a leading role on the transition propose this governance structure to the different stakeholders involved and agree upon a final structure. After this governance structure is adopted, they may develop a detailed referral pathway with practical examples demonstrating who one should contact for specific issues. The referral pathways should be developed in appropriate languages for circulation in refugee settlements. It is recommended to develop an extensive list of the type of questions that water users are likely to ask to guide this information. 
Particularly for the bodies representing refugees and host community end users, it is important that these structures are inclusive and representative. Feedback should be sought from the community whether the RWCs, WUCs, WSBs, and PSP operators reflect the diversity of the end users that they represent. The composition of these groups should be adapted as needed to ensure this is the case.

\section{Empower existing community structures to advocate for meeting their water needs}

Stakeholders should establish a structured approach to allow communities to advocate for their needs and priorities through the referral pathways raised above and through civil society.

The voices heard and listened to by stakeholders, and the levels of social inclusion in the transition process, will fundamentally be shaped by the community's power dynamics as well as cultural norms and discrimination. Raising people's awareness of issues of exclusion - and the physical, social and attitudinal barriers faced by some individuals - is an extremely powerful first step in ensuring that the sector works towards meeting the needs of the most marginalized.

Existing community structures such as the WUCs and RWCs should be empowered to advocate on accountability and governance issues that need addressing by the OPM, UNHCR and/or utilities. A role of NGOs in the transition should be in supporting existing community-based organizations (for women, youth, etc.) and CSOs through funding and/or capacity building to raise their own voices. CSOs often have ties to community grassroots and can reach marginalized and isolated groups, including women, more than formal community structures such as RWCs.

\subsection{CAPACITY BUILDING}

It is critical to ensure utilities and WASH stakeholders have the capacity and ability to build the tools mentioned in this chapter to improve equity, monitoring and inclusion, and run contextual analyses. Relevant training and ongoing support by specialists in community engagement, economics and accountability should be provided to utilities and other WASH stakeholders. 


\section{SUMMARY OF RECOMMENDATIONS}

The steps described below are recommended to be conducted over the coming 9-12 months during the current process of transition of water supply systems.

\begin{tabular}{|c|c|c|c|c|}
\hline Action & Step & $\begin{array}{l}\text { Inputs required } \\
\text { *Some workshops/consultations may be } \\
\text { combined, reducing the overall budget required }\end{array}$ & Timeline & Budget \\
\hline \multirow[t]{2}{*}{$\begin{array}{l}\text { 1. Prioritize capital investment } \\
\text { and harmonize tapstand } \\
\text { margins }\end{array}$} & $\begin{array}{l}\text { 1.1 Establish tools for prioritization and } \\
\text { decision making for capital investment to } \\
\text { ensure that investment needs are going } \\
\text { towards an equitable transition }\end{array}$ & $\begin{array}{l}\text { A WASH infrastructure and economics specialist } \\
\text { to work closely with UNHCR, GIZ, EWB-USA and } \\
\text { others to document case studies of capital } \\
\text { investment for system upgrades. Through } \\
\text { consultations and small workshops, the specialist } \\
\text { could draft the decision tree tool. This could be } \\
\text { taken up under existing projects, such as those } \\
\text { supported by KFW and the World Bank. }\end{array}$ & 3 months & 15,000 USD \\
\hline & $\begin{array}{l}\text { 1.2 Develop a process for determining and } \\
\text { harmonizing tapstand operator margin } \\
\text { rates }\end{array}$ & $\begin{array}{l}\text { A WASH infrastructure and economics specialist } \\
\text { to collect and analyse data on the parameters } \\
\text { affecting PSP rates across a range of systems. } \\
\text { They could develop a series of proposals for fixing } \\
\text { PSP rates on the basis of the data. Consultation } \\
\text { meetings with key stakeholders to be held to } \\
\text { adopt harmonized rates. }\end{array}$ & 3 months & 15,000 USD \\
\hline \multirow[t]{2}{*}{$\begin{array}{l}\text { 2. Develop sector-wide tools for } \\
\text { measuring the key parameters } \\
\text { of a successful utility transition }\end{array}$} & $\begin{array}{l}\text { 2.1 Establish a monitoring and learning tool } \\
\text { for assessing the performance of prepaid } \\
\text { communal water dispensers in tariff } \\
\text { payment transition }\end{array}$ & $\begin{array}{l}\text { A WASH M\&E specialist to draft the tool with key } \\
\text { parameters. Workshops to validate the tool. }\end{array}$ & 1 month & 5000 USD \\
\hline & $\begin{array}{l}2.2 \text { Establish a sector-wide approach to } \\
\text { testing and easing in of tariffs and }\end{array}$ & $\begin{array}{l}\text { A national level workshop to be convened by a } \\
\text { leading WASH agency to review tariffs } \\
\text { implemented so far, and to agree on a monitoring }\end{array}$ & 1 month & 5000 USD \\
\hline
\end{tabular}




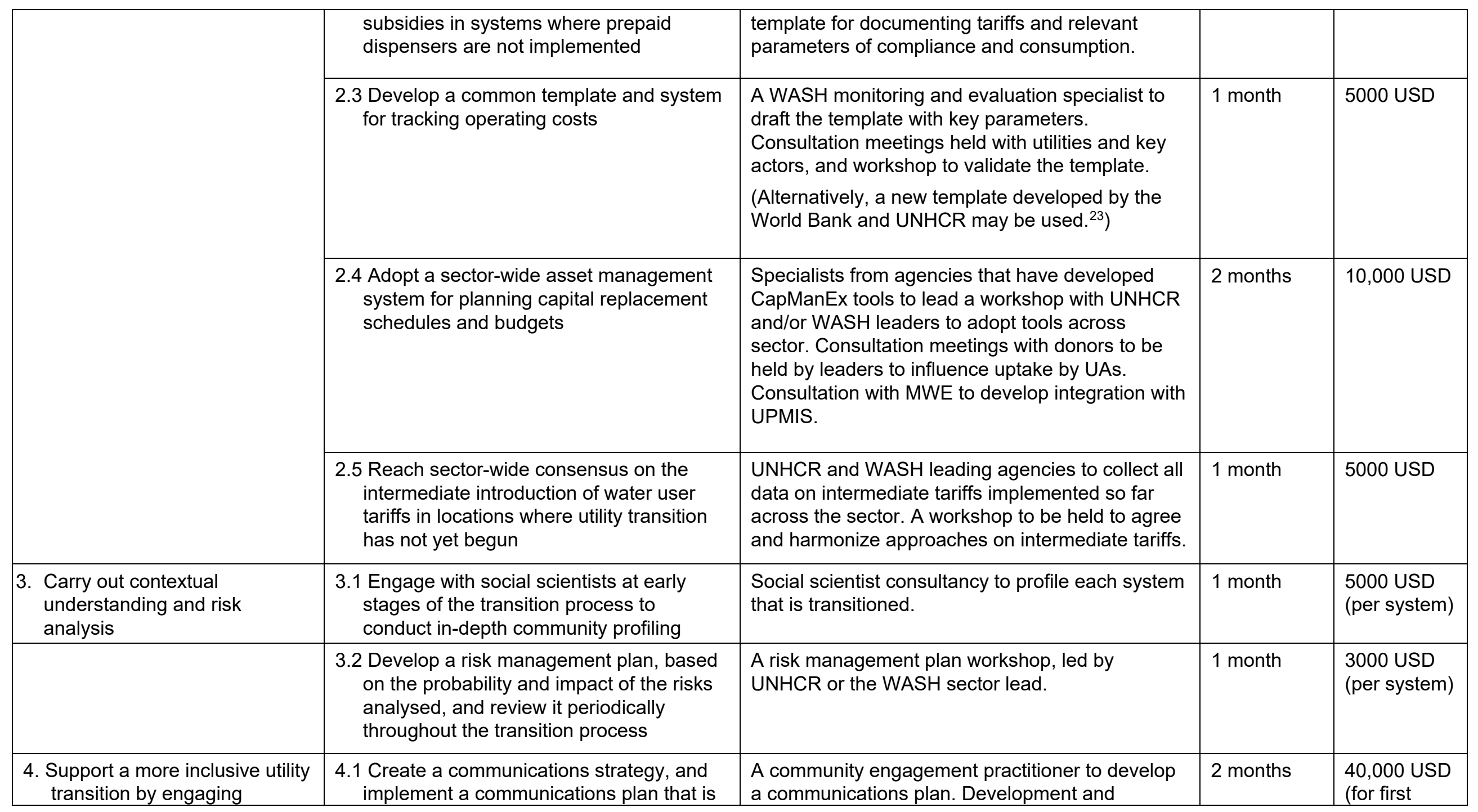




\begin{tabular}{|c|c|c|c|c|}
\hline \multirow{5}{*}{$\begin{array}{l}\text { communities, and establishing } \\
\text { communications plans, } \\
\text { community feedback } \\
\text { mechanisms and } \\
\text { opportunities for social } \\
\text { accountability }\end{array}$} & $\begin{array}{l}\text { targeted to the specific needs and } \\
\text { languages of the population }\end{array}$ & $\begin{array}{l}\text { production of communications materials for } \\
\text { targeted system. }\end{array}$ & & $\begin{array}{l}\text { plan, to be } \\
\text { replicated) }\end{array}$ \\
\hline & $\begin{array}{l}\text { 4.2 Develop and deploy a tool for measuring } \\
\text { community participation }\end{array}$ & $\begin{array}{l}\text { A community engagement and monitoring and } \\
\text { evaluation specialist to draft the participation tool, } \\
\text { followed by workshops with stakeholders to agree } \\
\text { on parameters. }\end{array}$ & 2 months & 10,000 USD \\
\hline & $\begin{array}{l}\text { 4.3 Support social accountability by creating } \\
\text { lists of key information that end users } \\
\text { have a right to know }\end{array}$ & $\begin{array}{l}\text { Workshops to be held at system level to develop } \\
\text { lists, followed by harmonization with national-level } \\
\text { information, and validation with stakeholders. }\end{array}$ & 1 month & 5000 USD \\
\hline & $\begin{array}{l}\text { 4.4 Develop detailed referral pathways } \\
\text { according to an agreed governance } \\
\text { structure }\end{array}$ & $\begin{array}{l}\text { Consultations to be held with different } \\
\text { stakeholders to agree on governance structure. } \\
\text { Workshop to be held to develop the referral } \\
\text { pathways. }\end{array}$ & 2 months & 10,000 USD \\
\hline & $\begin{array}{l}\text { 4.5 Empower existing community structures } \\
\text { to advocate on having their water needs } \\
\text { met }\end{array}$ & $\begin{array}{l}\text { Capacity building sessions for community } \\
\text { governance bodies and CSOs to be led by the } \\
\text { WASH focal agency. }\end{array}$ & 6 months & $\begin{array}{l}15,000 \text { USD } \\
\text { (per system) }\end{array}$ \\
\hline $\begin{array}{l}\text { 5. Build the capacity of utilities } \\
\text { and WASH sector } \\
\text { stakeholders }\end{array}$ & $\begin{array}{l}\text { 5.1 Provide training and capacity building to } \\
\text { implement recommendations } 1-4 \text {. }\end{array}$ & $\begin{array}{l}\text { Training and ongoing support from specialists in } \\
\text { community engagement, economics and } \\
\text { accountability for utilities and other WASH sector } \\
\text { stakeholders in the above methods. }\end{array}$ & 12 months & 60,000 USD \\
\hline
\end{tabular}




\section{BIBLIOGRAPHY}

Agua Consult and Water for People. (2015). CAPMANEX Tool.

Andres, L.A., M. Thibert, C. Lombana Cordoba, A.V. Danilenko, G. Joseph and C. Borja-Vega. (2019). Doing More with Less: Smarter Subsidies for Water Supply and Sanitation. World Bank. https://openknowledge.worldbank.org/handle/10986/32277

Bos, R. (2016). Manual on The Human Rights To Safe Drinking Water And Sanitation For Practitioners. IWA. https://iwa-network.org/wp-content/uploads/2016/08/Manual-Human-RightWater-Sanitation.pdf

Brown, J., \& van den Broek, M. (2018). A Model for Sustainable Management of Water Infrastructure in Ugandan Refugee Settlements and Hosting Areas. Action Against Hunger.

Burr, P. (2019). The State of WASH Financing in Eastern and Southern Africa: Uganda Country Level Assessment. Unicef. https://www.unicef.org/esa/sites/unicef.org.esa/files/201910/UNICEF-Uganda-2019-WASH-Financing-Assessment.pdf

David, G., Aykroyd, K., et al. Age and Disability Consortium. (2018). Humanitarian Inclusion Standards for Older People and People with Disabilities.

https://www.cbm.org/fileadmin/user upload/Publications/Humanitarian inclusion standards for older people and people with disabi....pdf

Day, S. and Forster, T. (2018). Water, Sanitation and Hygiene in Post-Emergency Contexts: A Study on Establishing Sustainable Service Delivery Models. UNHCR and Oxfam. https://oxfamilibrary.openrepository.com/bitstream/10546/620598/1/rr-wash-post-emergencydelivery-041218-en.pdf

Frade, J. (2019). Finance Assessment of the WASH Sector in Uganda. IRC. https://www.ircwash.org/sites/default/files/084201920report irc finance assessment of uganda water sector 0.pdf

Government of Uganda. (2017). Refugee and Host Population Empowerment (ReHoPE) Strategic Framework. https://data2.unhcr.org/en/documents/download/64166

Government of Uganda. (2018). Road map for the implementation of the Comprehensive Refugee Response Framework in Uganda, 2018-2020.

https://data2.unhcr.org/en/documents/download/64290

Heymans, C., K. Eales and R. Franceys. (2014). The Limits and Possibilities of Prepaid Water in Urban Africa: Lessons from the Field. Prepaid Water in Kampala: Case Study. World Bank. https://documents.worldbank.org/curated/en/499021468010486033/pdf/901590REPLACEMOPr epaidOWaterOAfrica.pdf

Jiménez, A., Kjellén, M., Le Deunff, H. (2015). Accountability in WASH: Explaining the Concept. UNICEF and UNDP.

https://www.unicef.org/wash/files/Accountability in WASH Explaining the Concept.pdf

Kobel, D. (2020). Water System Assessment and Service Transfer in the Uganda Districts Hosting Refugees: Policy and Institutional Implications. World Bank and UNHCR. 
Lister, S. (2010). Fostering Social Accountability. Guidance note. UN Development Programme (UNDP). https://www.undp.org/content/dam/undp/library/Democratic\%20Governance/OGC/dgogc-Fostering\%20Social\%20Accountability-Guidance\%20Note.pdf

National Water and Sewerage Company. (2016). Uganda Customer Charter.

Knight, L., Niederberger, E., O'Reilly, M. (2018). An Introduction to Community Engagement in WASH. Oxfam. https://oxfamilibrary.openrepository.com/bitstream/10546/620611/1/gdintroduction-community-engagement-wash-170119-en.pdf

Sphere. (2018). The Sphere Handbook: Humanitarian Charter and Minimum Standards in Humanitarian Response. https://spherestandards.org/wp-content/uploads/Sphere-Handbook2018-EN.pdf

Sauter, J. (2019). Socio-Economic Survey on Willingness and Capacity to Pay for the Provision of Safe Water in Rhino Camp, Arua District, Uganda. Malteser International.

Uganda MWE. (2009). Tariff Policy for Small Towns, Rural Growth Centres and Large Gravity Flow Schemes.

Uganda Ministry of Water and Environment (MWE) (2018). Clients Charter 2018-2022. https://www.mwe.go.ug/sites/default/files/library/CLIENTS\%20CHARTER\%202018-2022 0.pdf

Uganda MWE. (2019). Water and Environment Sector Response Plan for Refugees and Host Communities in Uganda.

https://www.mwe.go.ug/sites/default/files/library/Final\%20Water\%20and\%20Environment\%20S ector\%20\%20Refugee\%20Response\%20Plan.pdf

Uganda MWE. (2019). National Framework for Operation and Maintenance of Rural Water Infrastructure in Uganda.

https://www.mwe.go.ug/sites/default/files/library/O\%26M\%20Framework\%20for\%20rural\%20wa ter\%20services V6 24.07.2020.pdf

Uganda Ministry of Water, Lands and Environment. (1999). A National Water Policy.

https://www.ircwash.org/sites/default/files/824-UG99-18171.pdf

UN General Assembly. (2015). The human rights to safe drinking water and sanitation. General Assembly resolution 7/169. (18 November 2015).

https://undocs.org/pdf?symbol=en/A/RES/70/169

World Bank. (2019). Assessment of Water Service Delivery in Refugee Settlements in Uganda: Analysis and Recommendations. 


\section{NOTES}

1 https://data2.unhcr.org/en/country/uga. Data as of 31 March 2020.

2 Government of Uganda (2018). Road map for the implementation of the Comprehensive Refugee Response Framework in Uganda, 2018-2020.

3 Government of Uganda (2017). Refugee and Host Population Empowerment (ReHoPE) Strategic Framework.

4 The State of WASH Financing in Eastern and Southern Africa. Uganda Country Level Assessment. UNICEF, September 2019.

5 Communication with NWSC, Kamwenge Branch.

6 Assessment of Water Service Delivery in Refugee Settlements in Uganda: Analysis and Recommendations. The World Bank, October 2019a.

Water System Assessment and Service Transfer in the Uganda Districts Hosting Refugees. World Bank and UNHCR, March 2020.

7 World Bank, 2019a.

8 The Limits and Possibilities of Prepaid Water in Urban Africa: Lessons from the Field. Prepaid Water in Kampala: Case Study. Heymans, et al. The World Bank, August 2014.

9 CAPMANEX Tool. Agua Consult and Water for People.

10 Tariff Policy for Small Towns, Rural Growth Centres and Large Gravity Flow Schemes. Ministry of Water and Environment. The Republic of Uganda, 2009.

11 Socio-Economic Survey on Willingness and Capacity to Pay for the Provision of Safe Water in Rhino Camp, Arua District, Uganda. Malteser International, July 2019.

12 National Water and Sewerage Company, Uganda Customer Charter, 2016.

13 Ugandan MWE. (2018). Clients Charter 2018-2021.

14 Ugandan Ministry of Water, Lands and Environment. (1999). A National Water Policy.

15 Uganda MWE. (2019). National Framework for Operation and Maintenance of Rural Water Infrastructure in Uganda.

16 Andres, Luis A., Michael Thibert, Camilo Lombana Cordoba, Alexander V. Danilenko, George Joseph, and Christian Borja-Vega. 2019. Doing More with Less: Smarter Subsidies for Water Supply and Sanitation. World Bank, Washington, DC.

17 World Bank, 2019a.

18 World Bank and UNHCR, 2020.

19 World Bank, 2014

20 Malteser International, 2019.

21 World Bank and UNHCR, 2020.

22 A Model for Sustainable Management of Water Infrastructure in Ugandan Refugee Settlements and Hosting Areas. ACF, University of Portsmouth, Practica Foundation, April 2018.

23 Kobel, Dorothy. (2020). Water System Assessment and Service Transfer in the Uganda Districts Hosting Refugees: Policy and Institutional Implications. World Bank and UNHCR, 2020.

A Transition for All: Supporting equity and community engagement in the transition of management of water supply systems to utilities in refugee settlements in Uganda 


\section{Research reports}

This research report summary was written to share research results, to contribute to public debate and to invite feedback on development and humanitarian policy and practice. It does not necessarily reflect the policy positions of the publishing organizations. The views expressed are those of the authors and not necessarily those of the publishers.

This report was produced by Oxfam's Global Humanitarian WASH team and was written by John Allen and Caroline Muturi, with contributions from Timothy Forster, Vincent Ogira and Eva Niederberger. Thanks to UNHCR and Oxfam Germany and their supporters for backing this work. We also thank the refugees, host communities and WASH sector stakeholders in Uganda who participated in this research.

This document is a summary report. The full report is available at the Oxfam WASH website: https://www.oxfamwash.org/

For more information, or to comment on this report, email: john.allen@oxfam.org.

(C) Oxfam International and UNHCR December 2020

This publication is copyright but the text may be used free of charge for the purposes of advocacy, campaigning, education, and research, provided that the source is acknowledged in full. The copyright holder requests that all such use be registered with them for impact assessment purposes. For copying in any other circumstances, or for re-use in other publications, or for translation or adaptation, permission must be secured and a fee may be charged. Email policyandpractice@oxfam.org.uk.

The information in this publication is correct at the time of going to press.

Published by Oxfam GB for Oxfam International under ISBN 978-1-78748-729-1 in December 2020. DOI: $10.21201 / 2020.7291$

Oxfam GB, Oxfam House, John Smith Drive, Cowley, Oxford, OX4 2JY, UK.

\section{UNHCR}

UNHCR WASH is the Water, Sanitation and Hygiene Unit of the United Nations Refugee Agency (UNHCR). Its operations in more than 50 countries ensure the delivery of water and sanitation services to millions of refugees in camps, outside of camps and in urban settings.

\section{OXFAM}

Oxfam is an international confederation of 20 organizations networked together in 67 countries, as part of a global movement for change, to build a future free from the injustice of poverty. Please write to any of the agencies for further information or visit www.oxfam.org. 